\title{
O DEPARTAMENTO DE TEORIA LITERÁRIA E LITERATURA COMPARADA: PRIMÓRDIOS*
}

http://dx.doi.org/10.11606/issn.2237-1184.v0i33p12-27

Adelia Bezerra de Meneses ${ }^{\mathrm{I}}$

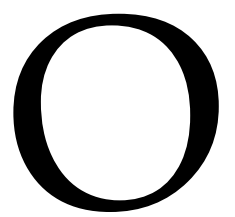

Professor Antonio Candido dizia que, depois de uma certa idade, falar da história pessoal é muitas vezes fazer a história de uma geração. Com isso justifico o tom de inevitável biografismo que permeará essas paginas: é impossível para mim falar da história do Departamento de Teoria Literária e Literatura Comparada sem mesclar a esse esforço de reflexão, inescapavelmente, meu percurso pessoal. A minha intenção aqui é, com a ajuda da memória e de alguns documentos de arquivo pessoal, privilegiar sobretudo os primórdios do DTLLC da USP, aí incluindo sua pré-história.

"Teoria Literária" foi para mim inicialmente uma matéria do primeiro ano de faculdade, ministrada por Antonio Candido em 1962, na Maria Antonia, no Curso de Letras Clássicas. Recém implementada no curriculum de Letras pelo Professor, essa disciplina foi a semente do que viriam ser os Departamentos de Teoria Literária e Literatura Comparada, tanto da USP quanto da UNICAMP.

Estávamos na Faculdade de Filosofia, Ciências e Letras da USP, quando situada na Maria Antonia, antes portanto do golpe de 64, que implantou a Ditadura civil-militar no Brasil (o que num primeiro momento em nada arrefeceu a efervescência cultural e o sopro revolucionário

\footnotetext{
* Depoimento de Adelia Bezerra de Meneses sobre a formação do Departamento de Teoria Literária e Literatura Comparada da Faculdade de Filosofia, Letras e Ciências Humanas da Universidade de São Paulo.

I Universidade de São Paulo, São Paulo, São Paulo, Brasil.
} 
daqueles anos tensos e intensos da década de 60, carregados de Utopia); e bem antes dos dramáticos acontecimentos de outubro de 1968, que provocaram a depredação e incêndio do prédio da FFCL e sua mudança forçada para a Cidade Universitária, na sequência do conflito com os estudantes do Mackenzie respaldados por forças da repressão da Ditadura.

Essa disciplina de primeiro ano era optativa, e eu a escolhi porque conhecia o professor das estantes de casa, como o Autor de Formação da Literatura Brasileira, livro que eu tinha andado consultando para fazer trabalhos de Literatura Brasileira no Colegial. Com olhos deslumbrados de adolescente, eu tive a sorte imensa de ter uma das minhas primeiras aulas de Faculdade, caloura ainda, com Antonio Candido. E isso marcou para sempre os rumos da minha vida, não apenas intelectual, não apenas profissional: essa convivência como discípula propiciou não somente uma maneira de pensar a Literatura, ou de pensar a Universidade, mas de pensar o Brasil, de pensar a vida. Ele nos fez viver uma aventura intelectual que forjou aquilo que cada um de nós se tornou.

Tratava-se de uma disciplina nova que entrara no curriculum de Letras em 1961, como "Teoria Geral da Literatura"1 e que em 1962 teve sua denominação alterada para "Teoria Literária e Literatura Comparada". O conceito de Teoria Literária foi sendo compreendido ao longo do curso: era uma disciplina que se dedicava à abordagem da natureza e função da Literatura e que nos fornecia ferramentas para seu estudo, além do repertório dos grandes textos propostos como objetos de análise. Por outro lado, o conceito de "Literatura Comparada" creio que nunca foi propriamente problematizado na época, era antes objeto de uma prática, e dizia respeito a não apenas se estudarem os textos literários, ultrapassando as fronteiras de literaturas nacionais, mas à postura de articular a Literatura a outros saberes, a outras áreas do conhecimento, a outras artes: Literatura e Psicanálise, Literatura e Filosofia, Literatura e Pintura , Literatura e Música, etc. Não por acaso, eu viria fazer, alguns anos mais tarde - e depois de um Mestrado mais, digamos, convencional (sobre a Crítica Literária de Álvaro Lins), sempre sob a orientação de Antonio Candido - uma tese de Doutorado sobre Chico Buarque, dentro do recorte de Literatura e $\mathrm{MPB}^{2}$; e em seguida, trabalharia na área de Literatura e Psicanálise; a posteriori posso afirmar que toda a minha produção acadêmica é, essencialmente, caudatária do Comparatismo, que me marcou singularmente.

As aulas de Teoria Literária, nesses inícios, eram dadas exclusivamente por Antonio Candido que, no entanto, logo começa a

\footnotetext{
${ }^{1}$ Essa disciplina, dada pela primeira vez em 1961, logo que Antonio Candido veio de Assis, teve como alunos Walnice Nogueira Galvão, Celso Lafer, Roberto Schwarz, Victor Knoll. Antonio Candido comentou que os trabalhos de fim de curso que essa turma fantástica fez para ele, foram todos publicados.

2 Cf. MENESES, Adelia Bezerra de: Desenho Mágico. Poesia e Política em Chico Buarque. São Paulo, Ateliê Editorial, 2002, 3a . ed.)
} 
formar sua equipe. Os primeiros recrutados para colaborarem no ensino de Teoria Literária são Roberto Schwarz e Walnice Nogueira Galvão. Roberto Schwarz dá aulas como "Auxiliar de Ensino", mas no fim da década de 60 vai para a França fazer seu Doutorado e, em seguida, para Yale, voltando ao Brasil só em 1978, quando integrará o Departamento de Teoria Literária da UNICAMP - como se verá mais adiante. Walnice, desde sempre "Assistente" de Antonio Candido, participa de todas as etapas da Teoria Literária e Literatura Comparada, fez seu Doutorado em 1970, e tornou-se a primeira Professora Livre-Docente da área, em 1972. Na sequência, virão João Alexandre Barbosa, Davi Arrigucci Jr. e, depois, Lígia Chiappini Moraes Leite, Tereza de Jesus Pires Vara, Lucila Bernardet; o Professor Boris Schnaiderman, que também fez tese com Antonio Candido, bem como, nos anos 80, Marlise Meyer, ministrarão cursos de Pós-Graduação na área. Pois mesmo depois da Reforma que fez a "Faculdade de Filosofia, Ciências e Letras" tornar-se a atual "Faculdade de Filosofia, Letras e Ciências Humanas", no bojo da mudança para a Cidade Universitária em 1969, a Teoria Literária não se tornou ainda um departamento: tratava-se de uma área, esdruxulamente alocada, obedecendo a injunções de ordem burocrática, no "Departamento de Linguística e Línguas Orientais" - e assim ficou, até 1990, quando se tornou, finalmente, o Departamento de Teoria Literária e Literatura Comparada (DTLLC).

Volto ao fio condutor, minhas memórias de aluna de Teoria Literária, nos inícios dos anos 60, na Maria Antonia. Tenho um registro das aulas de primeiro ano dadas por Antonio Candido num caderno ${ }^{3}$ de folhas amareladas. A primeira página ostenta um título, "Teoria da Literatura"; uma data, 1962; e um subtítulo, "Introdução aos Estudos Literários", que se desdobrava em 5 sub-itens: 1) Matéria e forma da criação literária; 2) A classificação das obras; 3) Os recursos expressivos; 4) Análise de textos; 5) Noções de investigação literária. E uma primeira indicação bibliográfica: o livro de René Wellek e Austin Warren, na sua tradução espanhola da Gredos.

Guardado ciosamente por tanto tempo, sobrevivendo a mudanças de casa e às turbulências da vida, algo de precioso esse caderno haveria de conter. Seleciono anotações que comparecem logo nas primeiras páginas, sob o tópico de "Função da Literatura". Elas dizem da "importância da Literatura como fator de humanização do Homem"; da "possibilidade de iniciação numa ordem de valores que nos fazem mais humanos"; dessa "disciplina humanizadora que torna o homem capaz, não de se ajustar, mas de se sentir suficientemente inquieto para mudar o seu tempo". E ainda: "A Literatura fornece uma visão do Homem e do Mundo"; "cada

\footnotetext{
${ }^{3}$ Inevitavelmente, serei obrigada a repetir aqui algo já registrado no texto "Anotações de uma Aluna", publicado em FONSECA, Maria Augusta; SCHWARZ, Roberto (orgs.). Antonio Candido 100 Anos. São Paulo: Editora 34, 2018.
} 
livro de Literatura deve alterar nossa sensibilidade, mudar a visão de mundo". Não poderia haver nada de mais motivador para uma meninada composta de calouros. Nessa apresentação inaugural de "Literatura", ressalto a sua função humanizadora, que tinha a ver com a "organização da experiência". Efetivamente, esse topos frequentará o pensamento e a práxis do Mestre e retornará ao longo dos anos, em outros cursos e palestras, como um leit-motiv, até ter sua formulação plenamente desabrochada no texto seminal "O Direito à Literatura", desses que marcam uma cultura, em que o Autor defende a ideia de que se a Literatura organiza a experiência, e humaniza, deveria consistir em um dos Direitos Fundamentais do Homem.

Com 18 anos de idade eu tinha escolhido Letras porque gostava de Literatura (e de Psicologia), - mas de repente alguém me formulava os motivos pelos quais valeria a pena empenhar toda a energia intelectual nesse projeto de estudo, que se tornou um projeto de vida. E ainda, com a abertura propiciada pela Literatura Comparada, poderia mergulhar na Literatura Brasileira (que era um projeto também, digamos, de militância ideológica), sem precisar abandonar a Literatura Grega (motivo da escolha de Letras Clássicas), nem o interesse pelas ciências do Inconsciente poderia, por exemplo, articular Literatura e Psicanálise!

Malgrado o intento de teorizar (latente no próprio nome da disciplina) sobre o fenômeno Literatura, privilegiava-se o texto literário. Havia uma preocupação por parte do Professor de nos confrontar sem mediações com a Literatura, apostando em seu poder transformador. Era assim que ele nos forjava a sensibilidade. E, como diz Carlos Drummond de Andrade no poema que fez a Antonio Candido por ocasião dos seus sessenta anos, esse professor que "sente a pulsação oculta da obra", que "conhece e pratica a força imponderável da intuição", que está sempre "a vislumbrar no poema/ para além das palavras uma conquista do inexprimível"4, viabilizava aos seus alunos esta experiência.

\section{Pós-Graduação}

Depois da Graduação, vinha uma Pós-Graduação em Teoria Literária e Literatura Comparada em duas fases: a primeira, no "Regime Antigo", em 1967-1968, ainda na Maria Antonia; e a segunda, no "Regime Novo" já na Cidade Universitária, de 1969 em diante. (Talvez importe dizer que no meu caso pessoal o "segundo tempo" da Pós, por conta de uma estada na Alemanha, que se estendeu de dezembro de 1968 a julho de 1971,

\footnotetext{
${ }^{4}$ Carlos Drummond de Andrade: "Esboço de Figura". Importa dizer que o poema prossegue, apontando, como não poderia deixar de ser, a dimensão "social" do ethos de Antonio Candido, alguém que "desdenha a provar os frutos da árvore da opressão/ e, fugindo ao séquito dos poderosos do mundo,/ acusa a transfiguração do homem em servil objeto do homem".
} 
aconteceu a partir de 1972, quando iniciei o Mestrado, finalizado em 1975, seguido pelo Doutorado, defendido em 1982.

Continuando o horizonte aberto na Graduação, a Pós-graduação com Antonio Candido pautou a atuação de muitos de nós como futuros docentes dos Departamentos de Teoria Literária tanto da USP quando da UNICAMP, sugerindo modelos para grades curriculares, inspirando montagens de programas e minutas de cursos. E sobretudo nos marcando com essa aderência ao texto e com a postura de relacionar Literatura e Sociedade, articulando uma visada estética a uma visada histórica. Semelhante ao que se passou na Graduação, tenho cadernos que registram notas de aulas desses cursos - ideias que serviriam de lastro para minha atuação profissional posterior, bem como a de colegas.

À guisa de ilustração, cito uma das disciplinas então ministradas por Antonio Candido em 1967 (o ano em que ele retornou ao Brasil, depois de uma temporada de aulas dadas na Sorbonne), que tinha como título "A Linguagem Poética". Como todas as demais, era anual, comportando uma parte teórica (Teoria da Poesia) e uma parte prática (Análise de poemas). Os itens que expandem o título da disciplina são: 1) Criação e Expressão; 2) Elementos expressivos básicos; 3) A Linguagem figurada; 4) Verso, Forma e Poesia; 5) Problemas de Análise e Interpretação. A agenda de trabalhos práticos implicava a elaboração de comentários críticos de Benedito Nunes (Introdução à Filosofia da Arte), Cleanth Brooks e R. P. Warren (A Natureza Orgânica do Poema), I. A. Richards (Princípios de Crítica Literária). A parte prática comportava análises, muitas, desde Gregório de Matos a João Cabral de Melo Neto.

Ao fim do curso, foi solicitado um "Trabalho de aproveitamento", mais alentado. Importa dizer que essa tarefa era personalizada, artesanalmente conduzida, isto é, Antonio Candido escolhia um tema diferente para cada um de seus orientandos: propunha trabalhos que "combinavam" com o aluno em questão, que tocavam em seus pontos de interesse. E para esta orientanda aqui, a tarefa solicitada tinha o seguinte tema (escrito datilografado pelo Professor, numa folha que me foi entregue em mãos), assim formulado: "Qual a importância da ideia de organização da experiência para um método objetivo de análise literária do poema"? Era um trabalho de aproveitamento de um curso de 1967 - mas 50 anos depois eu continuo às voltas com isso.

Ainda no Regime Antigo, portanto, ainda na Maria Antonia, a PósGraduação sob a batuta de Antonio Candido implicava no cumprimento de créditos em disciplinas ministradas por outros professores, que ele nos mandava cursar. Eu ia dizer, diplomaticamente, que ele nos "sugeria", mas, de fato, era uma determinação do Orientador. E foi assim que em 1968 eu fiz um curso de Sociologia da Literatura com Rui Coelho ("Problemas da Personalidade na Literatura" - em que o professor dissertava largamente sobre Proust) e um curso de Cinema e Literatura com Paulo Emílio Salles 
Gomes. Mais tarde, viria um Curso de Teatro com Décio de Almeida Prado. Faltaria a Dona Gilda para podermos afirmar que tivemos como professores o núcleo duro (o núcleo diamantinamente precioso) do Grupo de Clima? Mas, na realidade, não faltou: na Pós-Graduação "Regime Novo" (já Cidade Universitária), a Professora Gilda Mello e Souza deu Cursos sobre Estética do Modernismo - sendo que o de 1972 foi a sementeira de onde brotaram as teses de Doutorado em Teoria Literária, tanto do João Lafetá, sobre Mário de Andrade, quanto de José Miguel Wisnik, sobre a Música e a Semana de Arte Moderna.

Folheio agora o caderno de 1972, da Pós-Graduação Regime Novo (com anotações da disciplina ministrada pelo Professor Antonio Candido, "Os Fundamentos da Análise Literária", que se desdobrou de 4 de abril a fim de junho. Para o fim do semestre, estavam previstos encontros individuais para prestação de contas das leituras feitas. O eixo do programa foi o conceito de análise. Na primeira aula, o Professor distribuiu um papel mimeografado, contendo indicações sobre a Disciplina: o número de créditos (6), a carga horária (3 horas semanais); e o Programa, que passo a transcrever:

1. A análise no quadro dos estudos literários.

2. Pressupostos teóricos

3. Posição da Poética tradicional

4. Papel da "analyse de texte" e suas modalidades

5. Contribuição da Estilística. O círculo hermenêutico.

6. Contribuição dos formalismos. Noção de "estrutura".

7. Contribuição da Fenomenologia. As "camadas de sentido".

8. Contribuição da Psicanálise da imaginação e da Psicocrítica. A noção de "tema".

9. Contribuição da sociologia e do marxismo. As diferentes "reduções".

10. Adequação da análise ao objeto. Gênero, obra, fragmento.

11. O texto como composição específica.

12. O texto como integração da experiência.

Curso extraordinário, que exigiu muito de quem o ministrou, bem como dos alunos, mas que deu um lastro pelo qual a vida inteira eu vim agradecer. Dentre os 12 itens, creio que merecem destaque: A Poética Tradicional: Platão e Aristóteles; A Estilítica: Spitzer e Auerbach; A Psicanálise da Imaginação: Bachelard; A contribuição da sociologia e do marxismo; e O texto como integração da experiência. Na realidade, o que se viu no último item desse extraordinário curso foi o que se poderia chamar de "A crítica integrativa de Antonio Candido": de um lado, exercitando uma abordagem plural que, driblando os riscos do ecletismo, postula que no corpo a corpo com o texto, o crítico entre com tudo o que 
ele é, com tudo o que ele sabe: é a pessoa toda do analista de texto que entra em campo, não somente com o aparato metodológico da moda; e de outro lado, pondo em prática a regra de ouro da adequação do método ao objeto. Mas de todo esse voo panorâmico sobre a crítica, o que mais ficou evidente foi a simpatia e a afinidade profunda com a Estilística, e suas vinculações com a "analyse de texte" dos franceses, resgatada por Spitzer e por Auerbach. Efetivamente, a proposta dessa grande dupla, de ver na obra o "traço de estilo" que remeteria ao "traço de época" tem tudo a ver com a formulação candidiana do "externo" (o elemento da Sociedade) que se transforma em "interno" (o elemento da obra). Não por acaso, foi nesse curso que Antonio Candido nos contou que, quando saiu a publicação de Mimesis, antes de qualquer tradução para alguma outra língua europeia, ele contratou uma professora de alemão, para que pudesse ler com ela a obra magistral de Auerbach.

Além da disciplina de 3 horas-aulas por semana, e além dos colóquios individuais cuja frequência era ritmada pela evolução da pesquisa e pelos prazos de cada um, os orientandos tinham os "Seminários de Orientação", com uma programação específica (que valia por um outro curso, quase que mais exigente em termos de leituras). Isso se dava em encontros semanais, com discussão da bibliografia e apresentações periódicas a cargo dos participantes. Era como que um grupo de estudos de alto nível, coordenado pelo Orientador. Assim, por exemplo, o Seminário de Orientandos de 1973, que teve como tema "Literatura e Sociedade" , comportou a discussão de: Roger Bastide: Arte e Sociedade; Plekhánov: Sociologia da Arte; Trotsky: Literatura e Revolução; Caudwell: Ilusión y Realidad; Lukács: Ensaios de Literatura e Marxismo e Teoria da literatura; Lucien Goldmann: Por uma Sociologia do Romance; Adorno: Ensaio sobre Lírica e Sociedade; Walter Benjamin: A obra de Arte e sua reprodutibilidade técnica; Auerbach: Mimesis. De novo, Auerbach, e, como não poderia deixar de ser, finalizamos com Antonio Candido: Literatura e Sociedade. Marcante foi também o estudo de Goldmann, cuja "homologia estrutural" remetia a uma abordagem das relações entre Literatura e Sociedade similar à compreensão de Antonio Candido; e cuja noção de "visão de mundo", deslocando a percepção do indivíduo para a classe (- e reversivelmente), é extremamente operacional.

\section{Mestrado}

Volto um pouco na linha do tempo, para falar do Mestrado e da importância da FAPESP para o estabelecimento de "massa critica" em Teoria Literária. Com efeito, a Fundação de Amparo à Pesquisa do Estado de São Paulo, criada em 1960, e da qual Antonio Candido integrava o Conselho, teve um papel fundamental na consolidação da pesquisa nessa área. Na carta-ofício em que solicita uma bolsa de Pesquisa para a 
elaboração da minha dissertação de Mestrado, dirigida ao Prof. Oscar Sala, Diretor da FAPESP, e datada de 28 de outubro de 1971, Antonio Candido faz uma pontual apresentação do recorte geral das pesquisas por ele nucleadas, que tinham por intento fazer um levantamento da Crítica Brasileira. Com efeito, ao encaminhar à Fundação o meu projeto "A obra crítica de Álvaro Lins e usa função histórica" ele contextualiza essa proposta num quadro mais amplo, inaugurado, por sinal, por ele próprio - e isso, depois de ter apresentado a candidata com os convenientes elogios para a boa aceitação do projeto. Transcrevo o trecho que interessa:

\begin{abstract}
“[...] Eis por que convidei-a [a orientanda] para desenvolver uma investigação sobre problemas de interesse histórico e teórico, a fim de ampliar o projeto de levantamento sistemático das ideias críticas em nosso país, em alguns momentos importantes. Sumarizando para seu governo, lembro que eu próprio iniciei a tarefa para o período 1870-1915 com uma monografia sobre Sílvio Romero; José Veríssimo foi objeto de uma tese de doutoramento de João Alexandre Barbosa (1970); o movimento crítico do Modernismo, de 1920 a 1930, foi em parte levantado, através da obra de Mário de Andrade, nas dissertações de mestrado de Maria Helena Grembecki e Nites Teresinha Feres (1966) 5 , a completar, digo, a serem completadas pela investigação mais ampla que esta vem realizando para sua tese de doutoramento, que explora as manifestações críticas de vanguarda através de pequenas revistas, manifestos e panfletos; o decênio 1930-1940 é objeto da pesquisa de João Machado Lafetá, que estuda Alceu Amoroso Lima, Agripino Grieco, Otávio de Faria e a segunda fase de Mário de Andrade. A todos estes jovens estudiosos, apoiados pela Fundação, eu desejaria agora poder juntar, para o decênio 1940-1950, a presente candidata, cujo plano vai anexo." 6
\end{abstract}

Já se vê que a mestrandinha aqui não escolheu propriamente seu objeto de Dissertação, eu nunca teria pensado em Álvaro Lins: esse tema lhe foi docemente imposto pelo orientador, no pacote Mestrado/bolsa da FAPESP. Logo a dissertação virou livro, creio que por conta do nome do Orientador, publicada pela Editora Vozes, numa coleção dirigida por Paulo Sergio Pinheiro, então professor da UNICAMP, e que procurava títulos para publicações geradas de trabalhos de Pós-Graduação.

Por outro lado, no Doutoramento, o processo foi oposto: tive total liberdade para a escolha do tema da tese, dei muitas cabeçadas, redigi projetos que não foram adiante, tudo sob o olhar complacente do

5 Uma das coisas que Antonio Candido sempre relatava era a importância das pesquisas sobre Mário de Andrade (incluindo-se aí a da Telê Porto Ancona Lopes, além daquelas citadas no ofício à FAPESP) como germe inicial da incorporação do Acervo de Mário de Andrade ao IEB-USP.

${ }^{6}$ Tenho a cópia em carbono dessa carta, em papel de seda (que era como então se fazia com textos datilografados a serem reproduzidos, para que o rolo da máquina de escrever suportasse algumas cópias). 
orientador, até me focar em Chico Buarque. Ele já era um compositor consagrado, além de dramaturgo, tinha criado coisas de altíssima qualidade, mas estávamos em fins da década de 70, Chico nasceu em 1944 - não podia existir um "objeto de tese" mais contemporâneo. Não dá pra se imaginar, agora, o significado disso. Efetivamente, foi Antonio Candido que levou para a Universidade o estudo de autores contemporâneos, foi ele que começou a orientar teses sobre autores de uma geração um pouco anterior à dele, ou da idade dele, como Mário de Andrade (estudado por Telê Porto Ancona Lopes, Nites Terezinha Feres, Maria Helena Grembecki), Guimarães Rosa (trabalhado por Walnice Nogueira Galvão), Modernismo Gaúcho (Lígia Chiappini), Oswald de Andrade (Vera Chalmers), Murilo Rubião (Jorge Schwarz) etc, etc. Mas no caso de Chico Buarque, além da novidade de passar a orientar uma tese cujo autor era exatamente da mesma idade da orientanda, ele abriu a universidade para a MPB. Num parênteses, aliás, seria importante dizer que Antonio Candido, por volta de 1980, fez um texto crítico para Adoniram Barbosa, e que passou a figurar numa capa de disco do compositor do Bixiga. Além disso, também orientou um mestrado (1974) sobre as Histórias em Quadrinhos, essa nova modalidade de narrativa ficcional (de Antonio Luiz Cagnin). Era a práxis da Literatura Comparada em ação.

\section{Teoria Literária - UNICAMP}

Logo após a defesa do Mestrado, em 1975, foi a convite de Antonio Candido que comecei a dar aulas de Teoria Literária e Literatura Comparada na UNICAMP, integrando o grupo pioneiro de orientandos que Antonio Candido levou ${ }^{7}$ da USP para Campinas, para trabalharem na implantação do Instituto de Estudos da Linguagem (IEL) da UNICAMP. O Instituto tinha dois pilares iniciais, a Teoria Literária e a Linguística. Ao grupo dos linguistas Carlos Franchi, Haquira Osakabe, Carlos Vogt e Rodolfo Ilari - (todos ex-alunos), que já faziam parte do Departamento de Linguística então alocado no Instituto de Filosofia e Ciências Humanas da UNICAMP, Antonio Candido agregou sua primeira equipe de Teoria Literária: João Lafetá , Berta Waldman, Vera Chalmers, Suzi Sperber, Edda Arzua Ferreira, José Miguel Wisnik e eu - todos, seus orientandos. Já nessa fase Haquira Osakabe migrou da Linguística para a Teoria Literária. Esse grupo inicial incluía também Maria Lucia Dal Farra e Yara Frateschi Vieira. E em meio aos inevitáveis imbróglios políticos que cercavam o projeto de um novo Instituto na Universidade Estadual de Campinas, o Reitor Zeferino Vaz, admirador ferrenho de Antonio Candido, condicionou o apoio ao projeto da criação de um Instituto de Estudos da Linguagem na

\footnotetext{
7 'Mas se a entrada na UNICAMP foi "a convite", alguns anos mais tarde todos do IEL tivemos que fazer um concurso de efetivação no Serviço Público.
} 
UNICAMP à aceitação, por parte de Antonio Candido, de ser seu Diretor. E foi assim que Antonio Candido assumiu a Direção do IEL, tendo Carlos Franchi como vice. Ao longo de 1976-1977, ele ia uma vez por semana a Campinas, para participar da implantação do novo Instituto, despachando com seu Diretor Associado, Carlos Franchi, que assumia a parte burocrática do cargo. Era sempre às terças feiras, de manhã. Eu tive a sorte imensa de dar aulas nesse dia, então íamos juntos, de trem húngaro - que fazia o percurso São Paulo - Campinas em uma hora e 17 minutos. Essa linha, ou esse trem foi logo desativado, mas cumpriu a sua função de levar o Diretor do IEL ao Instituto que ele criara, durante o período de implantação, com a possível rapidez e comodidade; e de propiciar as riquíssimas conversas desse contador de causos. Acho que nunca cresci tanto na vida.

A esse grupo inicial, que estava formando o Departamento de Teoria Literária campineiro, agregaram-se nos anos seguintes outros ex-alunos de Antonio Candido: Roberto Schwarz, que chegou em 1978, Antonio Arnoni Prado, Marisa Lajolo. Depois vieram Alexandre Eulálio, Modesto Carone, Luiz Dantas, Iumna Maria Simon, Maria Eugenia Boaventura - além da prata da casa, ex-alunos da Linguística da UNICAMP.

Em 1979 Lafetá deixou a UNICAMP, quando saiu sua contratação pela USP, junto à área de Teoria Literária e Literatura Comparada, ao fim de um processo complicadíssimo, implicando num arquivamento que ninguém explicava, de motivação evidentemente política e contra a qual Antonio Candido lutou com todas as suas forças - estávamos em plena Ditadura. Por volta dessa mesma época, José Miguel Wisnik também deixou a UNICAMP, indo para a Literatura Brasileira na USP. Com a formalização institucional, todos os professores que tinham entrado "por convite" tivemos que fazer, devidamente, o Concurso de Ingresso.

Nesse meio tempo, o Professor Antonio Candido se aposentou na USP (em 1978) - e a observação a ser feita é que chocou a todos a velocidade com que tramitou o seu processo de aposentadoria, naqueles tempos escuros. É como se houvesse, nos escalões administrativos da Universidade de São Paulo, gente interessada em que ele deixasse os quadros ativos da USP. Ele continuou, no entanto, com as orientações de Mestrado e Doutorado, e a influência de sempre.

Eu tinha a impressão de que havia entre os dois Departamentos, da USP e da UNICAMP, uma relação de matriz/filial, com vários docentes circulando entre as duas universidades, com a grata particularidade de que também a filial contava com a figura central do criador da Teoria Literária presente. Um testemunho desse intercâmbio, para ficarmos num exemplo simples, pode ser encontrado no elenco de colaboradores do livro organizado em 1983, por Roberto Schwarz, Os Pobres na Literatura Brasileira. ${ }^{8}$ Efetivamente, dos 35 autores, 21 eram professores dos 2

8 Roberto Schwarz (org.): Os pobres na Literatura Brasileira. São Paulo: Brasiliense, 1983. 
departamentos de Teoria Literária de ambas as universidades ${ }^{9}$ irmanados nesse projeto tão caudatário do "pensamento radical" de Antonio Candido, focando não a elite, mas a classe subalterna.

A respeito do amálgama entre participantes das duas universidades em torno do Mestre, uma historiazinha - no registro do anedotário - é significativa: anos depois de sua saída, quando Antonio Candido voltou a Campinas para receber o título de Doutor Honoris Causa da UNICAMP, deparando-se lá com a turma de ex-alunos, explicitou o clima de familiaridade e afeto: "Ah, o meu gadinho.."

No entanto, não se há de escamotear as diferenças entre os dois departamentos, que foram se impondo ao longo dos anos, sobretudo com as baixas na turma de ex-orientandos. O DTL da UNICAMP ficou muito mais permeável aos Estudos Culturais que, aliás, se impuseram hegemonicamente por todo os rincões universitários do país, enquanto o DTLLC da USP resiste, com sua práxis de adesão ao texto e sua vinculação Literatura/Sociedade. E se a Revista do DTL/UNICAMP assumiu o nome marioandradino de "Remate de Males", a Revista do DTLLC/USP replica, sempre, não apenas o título do livro do Mestre, publicado em 1965, mas a sua marca vincada: Literatura e Sociedade.

A vinculação de Antonio Candido ao IEL/UNICAMP e o projeto por ele acalentado (e que não chegou a se efetivar, lamentavelmente), de um Instituto de Estudos Latinonoamericanos, fez com que se realizasse em 1983, sediado no IEL, o encontro do grupo que preparava uma história da Literatura Latino-americana (sob a direção de Ana Pizarro), com o patrocínio da Associação Internacional da Literatura Comparada. O encontro anterior, inicial tinha-se dado em Caracas, em 1982. Foi aí que conhecemos pessoalmente, em solo campineiro, Monegal, Cornejo Polar, e especialmente o grande crítico Ángel Rama, que tinha se tornado amigo de Antonio Candido, e que viria a morrer tragicamente num desastre de avião, pouco tempo depois. Ficou uma conversa cortada, e também ficou cortado o projeto de um Instituto Latinoamericano. ${ }^{10}$

\section{O Departamento de Teoria Literária e Literatura Comparada da}

\section{USP}

\footnotetext{
9 Senão, vejamos: em meio a outros autores, "de fora" do grupo dos professores literatos (como Laura Mello e Souza, Chico Alvim, José Paulo Paes, Zulmira Ribeiro Tavares, Silviano Santiago, e uns poucos outros), e contando com a participação dos uspianos da Literatura Brasileira, sempre muito próximos, avultam o bloco da Teoria Literária da USP e da UNICAMP - como se verá a seguir: Alexandre Eulalio, Vilma Areas, Antonio Dimas, Flávio Aguiar, Alcides Villaça, Roberto Schwarz, Walnice Galvão, Zenir Reis, Arnoni Prado, Francisco Foot, Lígia Chiappini, Marisa Lajolo, Davi Arrigucci Jr., Telê Porto Ancona Lopes, Maria Eugenia Boaventura, Vera Chalmers, Iumna Simon, Alfredo Bosi, Suzi Sperber, Modesto Carone, João Lafetá, Berta Waldman, Carlos Vogt, Jesus Durigan, Adelia Bezerra de Meneses, Haquira Osakabe, Teresa Vara.

${ }^{10}$ Mais tarde, na USP, criou-se o Centro Ángel Rama.
} 
Ingressei na USP, por concurso de seleção, em 1989, deixando a UNICAMP, onde me aposentei. Foi literalmente, uma volta à casa paterna. O Professor já estava aposentado, fazia tempo, e também a Walnice. Fiquei no DTLLC mais de 10 anos, ao fim dos quais me desliguei, continuando, no entanto, como "Professora Colaboradora Voluntária", atuando junto à Pós-Graduação, com orientações de Mestrado e Doutorado. (Eu queria ter tempo para escrever e sobretudo livrar-me da carga burocrática, intensíssima, pois já tinha cumprido a minha quota de serviço administrativo nos tempos inaugurais da UNICAMP; e agora repetia-se a situação de sermos um grupo pequeno, que não dava conta de preencher todos os cargos e comissões existentes: durante anos o DTLLC foi o departamento das Letras com o número mais reduzido de professores, embora com a mesma carga burocrática dos departamentos numerosos).

\section{Linhas de Pesquisa do DTLLC/USP}

Por volta do início dos anos 90 estavam estabelecidas 3 grandes áreas de pesquisa no DTLLC: "Literatura e Sociedade", coordenada pelo Prof. Davi Arrigucci Jr.; "Literatura Comparada", coordenada pelo Prof. João Alexandre Barbosa; e "Literatura e Psicanálise", coordenada pelo Prof. João Luiz Machado Lafetá. Tenho no meu arquivo um xérox meio apagado, com as apresentações resumidas de cada área, assinadas pelos respectivos coordenadores, e o elenco de professores que as integravam, com suas respectivas linhas de Pesquisa. Num único caso (Literatura e Psicanálise), havia a presença de um Professor de fora do Departamento, a saber, do DLM, Prof. Philippe Willemart; e também num único caso registrou-se a presença de um docente em duas linhas de pesquisa, a saber, a Profa. Ivone Daré Rabello, integrando o grupo de Literatura e Sociedade, ao mesmo tempo que o de Literatura, Psicanálise e Sociedade.

Dada a importância histórica desse texto, que faz um mapeamento preciso do Departamento no início dos anos 90, passo a transcrevê-lo:

\section{Literatura e Sociedade}

\section{Coordenador: Prof. Dr. Davi Arrigucci Júnior}

\section{Apresentação:}

"O estudo das relações entre Literatura e Sociedade, fundamentais parra a Área de Teoria Literária de nossa Universidade desde a obra pioneira de Antonio Candido, que formou a equipe inicial de pesquisa, continua constituindo uma linha histórica de investigação da maior importância. Ao tratar de determinações básicas da obra de arte literária, do sistema de comunicação e da própria função da literatura, essa linha de estudos se entronca diretamente com vertentes centrais da tradição da 
crítica literária no Brasil, voltada desde as origens para os problemas decorrentes da inscrição do texto num contexto particular, para o relacionamento entre as obras e o público e as questões da própria forma estética em seus vínculos complexos com o processo histórico-social."

Assinado: Davi Arrigucci Jr.

Pesquisadores:

1.Ariovaldo José Vidal, MS-1, Linha de pesquisa: Prosa de Ficção e Sociedade;

2. Ivone Daré Rabello, MS-1, Linha de pesquisa: Prosa de Ficção e Sociedade;

3. Joaquim Alves de Aguiar, MS-2, Linha de pesquisa: Poesia e Sociedade;

4. Roberto Ventura, MS-3, Linha de pesquisa: Literatura e História;

5. Lígia Chiappini Moraes Leite, MS-5, Linhas de pesquisa: Literatura e História, Literatura e Ensino;

6. Davi Arrigucci Júnior, MS-5, Linha de pesquisa: Literatura e Sociedade.

\section{Literatura Comparada}

Coordenador: Prof. Dr. João Alexandre Barbosa

\section{Apresentação:}

“Dentre as várias tendências dos estudos literários contemporâneos, a Literatura Comparada vem ocupando um espaço cada vez mais importante, sobretudo em decorrência da própria evolução dos estudos teóricos, críticos e historiográficos, que buscam ver o fenômeno literário como, de um lado, necessariamente articulado a diversos campos do saber e, por outro, participando de princípios comuns às várias artes.

Sendo assim, a Literatura Comparada é hoje, quase por definição, o campo próprio da Teoria Literária (em países de língua inglesa os departamentos que tratam dessa disciplina são, por isso mesmo, chamados de Comparative Literature e, no caso de países como o Brasil, o estudo histórico-crítico da literatura é, cada vez mais, estudo comparado de literaturas geradoras e receptoras de motivos, temas e mesmo modelos de análise crítica.

Finalmente, é preciso acrescentar que o estudo comparado de gêneros, artes e poéticas se impõem como núcleos integradores das diversas investigações crítico-históricas desenvolvidas nas mais diferentes literaturas."

Pesquisadores:

Assinado: João Alexandre Barbosa. 
1. Cláudia Arruda Campos, Professora Assistente, MS-2, Linha de Pesquisa: Literatura e Arte Dramática;

2. Iná Camargo Costa, Professora Assistente, MS-2, Linha de Pesquisa: Literatura e Arte Dramática;

3. João Alexandre C. Barbosa, Professor Titular, MS-6, Linha de Pesquisa: Literatura e outras artes.

4. Regina Lúcia Pontieri, Professora Assistente MS-2, Linha de Pesquisa: Prosa e ficção contemporânea: Clarice Lispector e Virgínia Wolf;

5. Rita de Cassia Natal Chaves, Professora Assistente, MS-2, Linha de Pesquisa: Literatura Brasileira e literaturas africanas de expressão portuguesa;

6. Sandra Margarida Nitrini, Professora Assistente Doutora, MS-3, Linha de Pesquisa: Literatura Comparada no Brasil (História, Teorias e Ensaios Críticos).

\section{Literatura, Psicanálise e Sociedade}

Coordenador: Prof. Dr. João Luiz Machado Lafetá

\section{Apresentação:}

“No estudo das relações entre Literatura e sociedade é preciso estabelecer uma série de mediações, cujo conhecimento é imprescindível para o entendimento dos mecanismos da criação cultural. Neste sentido, além de noções como a de grupo social (mediação importante para especificar os interesses em jogo no universo ideológico), devem-se reconhecer níveis mais particularizados de elaboração: o âmbito do autor enquanto indivíduo, personalidade própria no interior do grupo, deve ser estudado como uma das instâncias decisivas do processo criativo. A relevância da Psicanálise como instrumento de interpretação literária situa-se neste ponto em que se interpenetram questões sociais amplas e tensões psicológicas vividas, transformadas e projetadas pelo sujeito na linguagem artística. A utilização de categorias psicanalíticas visa a atingir melhor conhecimento destes processos, reconhecendo-os na trama simbólica criada pela (e na) linguagem."

Assinado: João Luiz Lafetá.

Pesquisadores:

1. Philippe Willemart, Professor Titular, MS-6, - Departamento de Línguas Modernas, Linha de pesquisa: A arte da criação através das categorias psicanalíticas;

2. João Luiz Machado Lafetá, Professor Assistente Doutor, MS-3, Linha de Pesquisa: O imaginário e o simbólico na obra de Graciliano Ramos; 
3. Adelia Toledo Bezerra de Meneses, Professora Assistente Doutora, MS3, Linha de Pesquisa: O sonho na confluência da Literatura e da Psicanálise; 4. Cleusa Rios Pinheiro Passos, Professora Assistente Doutora, MS-3, Linha de Pesquisa: A poética do desejo na obra de Guimarães Rosa;

5. Ivone Daré Rabello, Auxiliar de Ensino, MS-1, Linha de Pesquisa: Idades Psíquicas do narrador e fabulação em Contos Novos. Como se vê, nesse último caso, a Prof. Ivone duplicou sua pertinência às áreas de "Literatura, Psicanálise e Sociedade" com "Literatura e Sociedade".

Aqui já estamos com o DTLLC da USP estabelecido como um Departamento autônomo, em plena floração, longe dos "Primórdios", cujo delineamento, na fidelidade ao título do meu texto, era meu objetivo.

Termino com algo que, antes de pertencer a um arquivo, tem a ver com o baú dos afetos, e que reencena com força minha história acadêmica pessoal, tão entranhada à Teoria Literária e Literatura Comparada. Tratase de uns versos "de cordel", ou, como nomeou sua autora, um "repente do sertão", recitado pelos alunos na festa de despedida que fizeram, no meu último dia de aula (ao menos na Graduação), em fins de 2000. Foi uma festa surpresa, com o convidado de honra, Antonio Candido, presente.

O repente é longo, e sua autoria - descobriu-se logo - é de uma aluna de Teoria Literária e Literatura Comparada, Maria Lucinéia de Almeida, a Néia, que também era funcionária do DTLLC. O texto retoma tópicos do programa, cita posturas, autores e temas trabalhados ao longo do curso, fala várias vezes de Antonio Candido e suas ideias, sobretudo da Literatura como "organizadora da experiência" e da "função humanizadora" da Literatura. A emoção não podia ser maior: no meu último dia de aula regular do curso de Teoria Literária na USP, ouço da boca de alunos aquilo que eles escutaram de mim, repetindo o que eu ouvira de Antonio Candido no primeiro dia de aula que tivera com ele, na Maria Antonia, quase 4 décadas antes - e com o Mestre presente. Parece que o círculo se fecha.

Transcrevo algumas estrofes:

Isso aqui, caro colega
É um repente do sertão
Eu não sei fazer poesia
Mas tenho um coração
Carregado de afeto
E uma imensa gratidão
Com essa mestra amiga
Digna de admiração

Adelia muito obrigada Nos anos de convivência No trabalhar da palavra Exercício e paciência 
Ensinando a ser leitor

A encontrar na Ciência

Literária que ensina

E organiza a experiência

$[\ldots]$

O exercício da vida

Ensina a organizar

Todos nossos sentimentos

Pra podermos repassar

Adelia herdou do Mestre

Que veio aqui comprovar

Literatura e afeto

Podem nos humanizar

$[\ldots]$

Ao Mestre Antonio Candido

Queremos agradecer

Pela ilustre presença

Que nos fez envaidecer

Essa rede literária

Que traduz esse saber

Adelia honra desde sempre

O Mestre que pôde ter.

Adelia Bezerra de Menezes graduou-se em Letras Clássicas em 1965, tornou-se mestre em 1975 e doutora em Teoria Literária e Literatura Comparada em 1981 pela Universidade de São Paulo. Foi docente de Literatura Brasileira no Leitorado de Romanística da Technische Universität de Berlim, professora de Teoria Literária e Literatura Comparada na USP e na Universidade Estadual de Campinas, onde se aposentou. Atualmente, é professora colaboradora voluntária na Unicamp e orientadora em pós-graduação do Departamento de Teoria Literária e Literatura Comparada da USP. Entre suas principais publicações estão Desenho Mágico: Poesia e Política em Chico Buarque (2002), Do Poder da Palavra: ensaios de literatura e psicanálise (2004) e Cores de Rosa: ensaios sobre Guimarães Rosa (2010). Contato: adeliabm@terra.com.br

ORCiD: https://orcid.org/0000-0002-0906-8680 